\title{
Efforts underway to prevent foot-and-mouth disease
}

T he foot-and-mouth disease (FMD) outbreak currently afflicting the livestock industries of the United Kingdom and other countries has raised awareness about the disease in the United States as well as questions about California's readiness to respond to an emergency.

As of May 7, there were 1,560 confirmed outbreaks in the United Kingdom, with about 2.5 million animals slaughtered since the outbreak began in February. Outbreaks have also occurred in the Netherlands, France, Ireland, Argentina, Brazil and Uruguay.

Although progress is being made on combating the disease, bans remain in place on exports of livestock, fresh meat and dairy products as well as animal movements from high-risk areas.

On April 23, the UC School of Veterinary Medicine at Davis conducted an educational seminar on FMD for more than 300 people in Tulare. Veterinary experts and government officials - including U.S. Department of Agriculture (USDA) deputy director Alfonso Torres, state veterinarian Richard Breitmeyer and California Secretary of Agriculture William Lyons - answered questions from cattle, sheep and swine producers about risks, quarantines, compensation, advances in vaccines and other aspects of FMD prevention and control.

British farmer John Carruthers, left, watches his lambs being carried off for slaughter. Although not infected by footand-mouth disease, more than 1,000 of his animals were destroyed in April because the disease was found on neighboring farms.

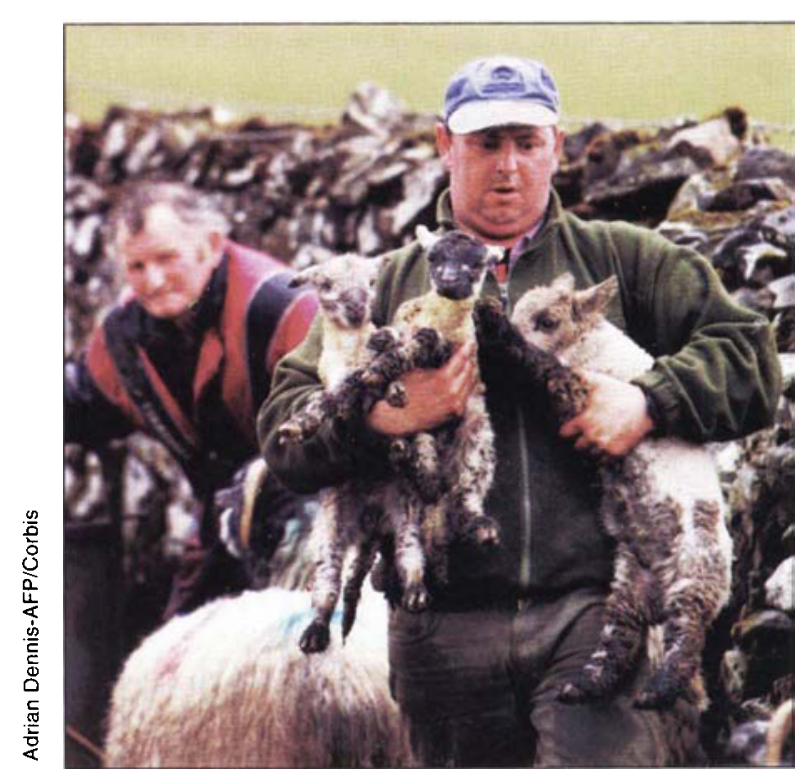

FMD is a highly contagious viral infection affecting cloven-footed domestic and wild animals. FMD is not considered a human health threat, and California has not experienced an outbreak since 1929. But because it is so contagious and devastating to animal health and farm livelihoods, FMD remains a serious animal health concern and a threat to California's beef, dairy and swine industries.

FMD is transmitted by infected or exposed animals and can also be introduced by shipments of infected meat or other products. The virus can be physically carried to other farms by people, facilities, equipment, motor vehicles, water, hay, feed, hides, clothing or pharmaceuticals. Airborne spread is possible up to 40 miles over land and 180 miles over water. Outbreaks are usually controlled by "stamping out," which means authorities establish quarantines, slaughter sick and exposed animals, dispose of animals and disinfect all facilities that have come into contact with the virus.

Economic impacts. The approximate value of related food animal products (milk, beef, lamb, wool) in California was about $\$ 5.4$ million in 1999. Because the virus spreads so quickly, an FMD outbreak could be an economic disaster to all of the state's livestockrelated industries. Exports would be halted, and animal movement - even among those that do not get FMD - would be severely restricted due to restrictions in international trade agreements.

In the United Kingdom, industries as disparate as thoroughbred racing and tourism have felt the repercussions of the FMD outbreak. Rebuilding farm industries and breeding programs would be a slow and costly process.

Facing an outbreak. USDA takes the lead on FMD diagnostics, control and research. Federal officials already limit imports of meat products from certain countries and have stepped up measures to exclude FMD from the United States. In response to the FMD outbreak, USDA increased its inspection budget by $\$ 32$ million and is hiring 350 new inspectors for airports, borders and ports. It is also 
educating travelers, shippers and caterers about handling garbage.

CDFA has also updated its emergency response protocols. If an animal shows symptoms of FMD, it is likely that a producer and local veterinarian would be the first to recognize and report it to CDFA, which would alert the USDA to confirm a diagnosis in the laboratory. Once the disease was verified, CDFA officials would set up quarantines and begin the stamping out process. Carcasses would be buried or burned, and all facilities would be disinfected. Diseasefree status can be regained 1 year after an outbreak has been controlled.

UC's role. The UC School of Veterinary Medicine's primary role is to educate industry producers, members of the public, government representatives and, of course, veterinarians, who are on the front lines of recognizing and reporting foreign animal diseases. Several faculty members and alumni have already traveled to the United Kingdom to assist in the FMD crisis. Eleven faculty members have undergone foreign animal disease training at USDA's Animal Disease Center on Plum Island, New York, and more than 25 have expertise in related disciplines. The school's California Animal Health and Food Safety

\section{Is vaccination the answer?}

Some countries vaccinate against FMD, usually where cases are reported regularly and producers accept reduced productivity of their most valuable animals as an alternative to fullblown epidemics. These countries do not export meat or related products to FMD-free countries.

In countries where FMD has been introduced, vaccination can help authorities control widespread epidemics, but immunization has several limitations.

First, no FMD vaccine can protect all animals against all strains of the disease. Some vaccinated animals would still get the disease, although most symptoms are reduced. It takes several days for the vaccine to become effective. If the vaccine fails or animals are moved during the waiting period, vaccinated animals could carry the virus to other livestock. Even when effective, vaccine protection wears off quickly.

Animals need revaccination every 6 to 12 months, which involves not only expense but a long-term commitment.

Since current tests cannot determine whether an animal has been exposed to the disease or been immunized, FMD-free nations ban animal products from countries which vaccinate. Meat from countries with vaccination programs is worth roughly $60 \%$ of the price that FMD-free countries can demand for their products. International trade agreements mandate that countries with vaccination programs must wait 2 years after the last vaccination to re-enter world markets.

Scientists believe that the United States is at least 3 years away from improved, faster-acting vaccines. For now, to maintain its valuable FMD-free status, the United States maintains its policy of exclusion and stamping out.
During the 1920s, foot-and-mouth disease affected 953 California cattle herds, resulting in the loss of 113,446 animals. The disease has not resurfaced in the United States since 1929. Above, Cows in Southern California were destroyed to prevent the highly infectious disease from spreading.

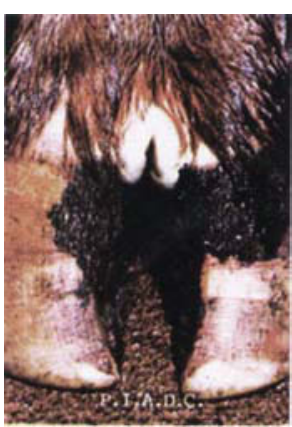

Foot-and-mouth disease may result in the formation of vesicles between a cow's toes, above. Other symptoms include blisters on the mouth, nose, feet and teats, which then rupture to leave ulcers. Due to sore feet, animals prefer to lie down. They may salivate excessively and stop eating. 